\title{
Patchiness of forest landscape can predict species distribution better than abundance: the case of a forest- dwelling passerine, the short-toed treecreeper, in central Italy.
}

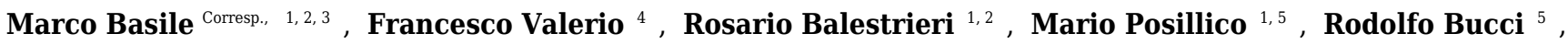 \\ Tiziana Altea ${ }^{5}$, Bruno De Cinti ${ }^{1}$, Giorgio Matteucci ${ }^{6}$ \\ 1 Istituto di Biologia Agroambientale e Forestale, Consiglio Nazionale delle Ricerche, Monterotondo Scalo, Italy \\ 2 Coordinamento MItO2000, Parma, Italy \\ 3 Chair of Wildlife Ecology and Management, Albert-Ludwigs-Universität Freiburg, Freiburg, Germany \\ 4 CIBIO/InBIO-UE - Research Center in Biodiversity and Genetic Resources. Pole of Évora Applied population and community ecology laboratory., University \\ of Évora UBC - Conservation Biology Lab, Department of Biology., Évora, Portugal \\ 5 Ufficio Territoriale Biodiversità di Castel di Sangro-Centro Ricerche Ambienti Montani, Corpo Forestale dello Stato, Castel di Sangro, Italy \\ 6 Istituto per i Sistemi Agricoli e Forestali del Mediterraneo, Consiglio Nazionale delle Ricerche, Ercolano (Na), Italy \\ Corresponding Author: Marco Basile \\ Email address: marcob.nat@gmail.com
}

Environmental heterogeneity affects not only the distribution of a species but also its local abundance. High heterogeneity due to habitat alteration and fragmentation can influence the realized niche of a species, lowering habitat suitability as well as reducing local abundance. We investigate whether a relationship exists between habitat suitability and abundance and whether both are affected by fragmentation. Our aim was to assess the predictive power of such a relationship to derive advice for environmental management. As a model species we used a forest specialist, the short-toed treecreeper (Family: Certhiidae; Certhia brachydactyla Brehm, 1820), and sampled it in central Italy. Species distribution was modelled as a function of forest structure, productivity and fragmentation, while abundance was directly estimated in two central Italian forest stands. Different algorithms were implemented to model species distribution, employing 170 occurrence points provided mostly by the MITO2000 database: an artificial neural network, classification tree analysis, flexible discriminant analysis, generalized boosting models, generalized linear models, multivariate additive regression splines, maximum entropy and random forests. Abundance was estimated also considering detectability, through $\mathrm{N}$ mixture models. Differences between forest stands in both abundance and habitat suitability were assessed as well as the existence of a relationship. Simpler algorithms resulted in higher goodness of fit than complex ones. Fragmentation was highly influential in determining potential distribution. Local abundance and habitat suitability differed significantly between the two forest stands, which were also significantly different in the 
degree of fragmentation. Regression showed that suitability has a weak significant effect in explaining increasing value of abundance. In particular, local abundances varied both at low and high suitability values. The study lends support to the concept that the degree of fragmentation can contribute to alter not only the suitability of an area for a species, but also its abundance. Even if the relationship between suitability and abundance can be used as an early warning of habitat deterioration, its weak predictive power needs further research. However, we define relationships between a species and some landscape features (i.e. fragmentation, extensive rejuvenation of forests and tree plantations) which could be easily controlled by appropriate forest management planning to enhance environmental suitability, at least in an area possessing high conservation and biodiversity values. 
1 TITLE

2 Patchiness of forest landscape can predict species distribution better than abundance: the case of

3 a forest-dwelling passerine, the short-toed treecreeper, in central Italy.

\section{AUTHORS}

5 Marco Basile $1,2,3,{ }^{*}$, Francesco Valerio ${ }^{4}$, Rosario Balestrieri ${ }^{1,2}$, Mario Posillico ${ }^{1,5}$, Rodolfo Bucci ${ }^{5}$,

6 Tiziana Altea ${ }^{5}$, Bruno De Cinti $^{1}$, Giorgio Matteucci ${ }^{6}$

\section{AFFILIATION}

$8{ }^{1}$ Consiglio Nazionale delle Ricerche, Istituto di Biologia Agroambientale e Forestale,

9 Monterotondo, RM, Italy

102 Coordinamento MITO2000, via Trento 49, I-43100 Parma, Italy

$11{ }^{3}$ Chair of Wildlife Ecology and Management, University of Freiburg, Tennenbacher Str. 4, D-

1279106 Freiburg, Germany

$13{ }^{4} \mathrm{CIBIO} / \mathrm{InBIO}-\mathrm{UE}$ - Research Center in Biodiversity and Genetic Resources. Pole of Évora

14 Applied population and community ecology laboratory. University of Évora UBC - Conservation

15 Biology Lab, Department of Biology. Mitra 7002-554 - Évora, Portugal

$16{ }^{5}$ Corpo Forestale dello Stato, Ufficio Territoriale Biodiversità di Castel di Sangro-Centro

17 Ricerche Ambienti Montani, Castel di Sangro, AQ, Italy

${ }^{6}$ Consiglio Nazionale delle Ricerche, Istituto per i Sistemi Agricoli e Forestali del Mediterraneo,

19 Rende, CS, Italy

$20 *$ corresponding author: marcob.nat@gmail.com

21 phone: +4915251417387 


\section{ABSTRACT}

Environmental heterogeneity affects not only the distribution of a species but also its local abundance. High heterogeneity due to habitat alteration and fragmentation can influence the realized niche of a species, lowering habitat suitability as well as reducing local abundance. We investigate whether a relationship exists between habitat suitability and abundance and whether both are affected by fragmentation. Our aim was to assess the predictive power of such a relationship to derive advice for environmental management. As a model species we used a forest specialist, the short-toed treecreeper (Family: Certhiidae; Certhia brachydactyla Brehm, 1820), and sampled it in central Italy. Species distribution was modelled as a function of forest structure, productivity and fragmentation, while abundance was directly estimated in two central Italian forest stands. Different algorithms were implemented to model species distribution, employing 170 occurrence points provided mostly by the MITO2000 database: an artificial neural network, classification tree analysis, flexible discriminant analysis, generalized boosting models, generalized linear models, multivariate additive regression splines, maximum entropy and random forests. Abundance was estimated also considering detectability, through N-mixture models. Differences between forest stands in both abundance and habitat suitability were assessed as well as the existence of a relationship. Simpler algorithms resulted in higher goodness of fit than complex ones. Fragmentation was highly influential in determining potential distribution. Local abundance and habitat suitability differed significantly between the two forest

44 stands, which were also significantly different in the degree of fragmentation. Regression showed that suitability has a weak significant effect in explaining increasing value of abundance. 
46 In particular, local abundances varied both at low and high suitability values. The study lends

47 support to the concept that the degree of fragmentation can contribute to alter not only the

48 suitability of an area for a species, but also its abundance. Even if the relationship between

49 suitability and abundance can be used as an early warning of habitat deterioration, its weak

50 predictive power needs further research. However, we define relationships between a species and

51 some landscape features (i.e. fragmentation, extensive rejuvenation of forests and tree

52 plantations) which could be easily controlled by appropriate forest management planning to

53 enhance environmental suitability, at least in an area possessing high conservation and

54 biodiversity values.

\section{INTRODUCTION}

In recent years considerable research effort has been involved in studying the influence of landscape patterns on biodiversity, triggered by the wide availability of biological data, as well as by the development of sophisticated species distribution models (SDMs), capable of predicting the presence of a species as a function of environmental variables (Elith \& Leathwick, 2009). The reliability of SDMs is based on the quality of occurrence data and the use of environmental predictors linked to species occurrence (Austin, 2007). For instance, presence data collected through nationwide standardised monitoring programmes provide enormous advantages in using SDMs, due to the creation of large databases (Elith \& Leathwick, 2009), hosting large amounts of occurrences and covering a wide, biologically significant area. Appropriate environmental predictors are those supposed to best describe the set of abiotic and biotic conditions affecting species occurrence, i.e. those characterising the species ecological 
68 niche (sensu Hutchinson; Hutchinson 1957; Holt 2009). Indeed, large-scale species distribution

69 modelling can be useful for addressing species-habitat relationships at multiple spatial scales in

70

71

72

73

74

75

76

77

78

79

80

81

82

order to understand the spatial variability in habitat selection (Farashi, Kaboli \& Karami, 2013;

Chefaoui et al., 2015; Morand et al., 2015). Also, considering the spatial heterogeneity in the

environment has become essential in many studies regarding reproduction, meta-population dynamics, gene flow, dispersal and connectivity (Bender, Tischendorf \& Fahrig, 2003; Wang et al., 2008; Ryberg et al., 2013). Recent studies have addressed this issue to propose alternative conservation strategies (Nixon et al., 2014), to monitor landscape change (Darvishi, Fakheran \& Soffianian, 2015) and to give insight into the distribution of native and non-native species (Kumar, Stohlgren \& Chong, 2006). Moreover, spatial patterns are considered major drivers of many ecosystem processes (Uuemaa, Mander \& Marja, 2013).

Although landscape heterogeneity may promote biodiversity due to the increase in habitat types (i.e. spatial heterogeneity) (Wiens, 1976; Loehle et al., 2005; Schindler et al., 2013), a highly diverse landscape arising from anthropogenic fragmentation may result in the loss of natural habitats and specialist species, which frequently require large patches of relatively unaltered habitat (e.g. extensive areas of well-preserved forests) (Marvier, Kareiva \& Neubert, 2004). Therefore, fragmentation can sometimes produce a simplification of the biological community, or biotic homogenisation across the landscape (McKinney \& Lockwood, 1999). Such a consequence derives from the loss of unique habitats, which are not replaceable in the short term (Fahrig, 2003).

Species abundance is also influenced by spatial variability, being affected by spatial gradients in the environmental parameters that form the environmental niche (Martínez-Meyer et al., 2013). Optimal conditions can be found where the environmental parameters are close to the centroid of 
91 the Hutchinsonian niche (Hutchinson, 1957). Hence, environmental variability can influence

92 both the presence and abundance of a species. Indeed, the decrease in abundance could warn

93 about a species decline in population and/or range extent earlier than a decrease in environmental

94 suitability. In fact, abundance could also be low in highly suitable regions, in response to local

95 limiting factors (VanDerWal et al., 2009).

96 The aim of our study was to investigate the relationship between environmental suitability and

97 abundance of a species, in response to fragmentation. However, true environmental suitability

98 can be expressed only by the whole set of environmental predictors and the local conditions that

99 can influence movements and interaction (Grinnell, 1917) and the persistence of those conditions

100 itself (Jackson \& Overpeck, 2000). Such an approach may be unfeasible, as in our case.

101 Therefore we refer to a restricted set of factors influencing local or regional environmental

102 suitability, i.e. some environmental predictors, which are supposed to be related to the

103 probability of occurrence, and concern habitat suitability (HS) (Franklin, 2009). Among those

104 habitats that can be highly modified by human activities, our research focused on forests, where

105 unsustainable timber harvest can result in a patchy landscape and alter the habitat, adversely

106 affecting forest biodiversity (Donald et al., 1998; Penman, Mahony \& Lemckert, 2005; Craig,

107 2007; Bearer et al., 2008; Shifley et al., 2008; Czeszczewik et al., 2014; Calladine et al., 2015;

108 Escobar et al., 2015). Woody plants are key elements in shaping the distribution of several bird

109 species such as birds (MacArthur, Recher \& Cody, 1966; Cody, 1985). Landscape structures and

110 the spatial arrangement of habitat patches can affect both the abundance and distribution of birds,

111 acting as structural bio-modifiers (Uuemaa, Mander \& Marja, 2013).

112 Therefore we selected as a model species a forest specialist bird, the short-toed treecreeper

113 (Family: Certhiidae; Certhia brachydactyla Brehm, 1820), and used landscape metrics as well as 
114 forest variables to characterise the forest landscape and weight habitat suitability. The short-toed

115 treecreeper is considered a forest-dwelling passerine, and hence a forest specialist, being a

116 secondary cavity nester (Newton, 1994). It is usually found in oak or mixed-deciduous forests

117 (with prevalence of oak), where it nests inside small holes excavated by woodpeckers or left by

118 dead branches (Cramp, 1988). It is a resident species, with very limited movements, usually

119 restricted to post-juvenile dispersal (Cramp, 1988). Home range and territory size can also be

120 very limited, sometimes less than 1 ha (Cramp, 1988). The global range extends through most of

121 central/southern Europe, up to Turkey and the Caucasus, overlapping with C. familiaris in

122 central Europe (BirdLife International, 2012). Thus we assessed whether there was a relationship

123 between local abundance and HS. We hypothesise that the realized niche can be altered by

124 fragmentation, resulting in lower HS and abundance. If such a relationship emerges, we aim to

125 estimate its predictive power and usefulness in forest management and in conservation policies.

126 In addition, we modelled HS with several algorithms and compared results, to assess whether

127 different species distribution models (SDMs) follow the same pattern of response.

\section{METHODS}

129 One of the main advantages offered by SDMs relies on the use of occurrence data collected with

130 different methods (Tsoar et al., 2007). Therefore we used occurrence records from multiple

131 sources, that spanned from year 2000 to 2013 . We relied mainly on the MITO2000 database

132 (Monitoraggio ITaliano Ornitologico, ITalian Ornithological Monitoring), an ongoing project

133 which started in 2000 and operates at a country-wide level (Fornasari et al., 2010). The project

134 uses point counts with unlimited radius (Blondel, Ferry \& Frochot, 1981), sampling points being

135 randomly selected within a $1 \mathrm{~km}^{2}$ grid square in the region of interest. Point counts were carried

136 out during a short time frame, from mid-May to mid-June. Occurrences of C. brachydactyla 
137 were also extracted from the databases of the National Forest Service (Ufficio Territoriale della

138 Biodiversità, Castel di Sangro, AQ), and the LIFE+ ManFor C.BD project, which employed a

139 sampling design similar to MITO2000, albeit at a smaller spatial scale $(\sim 200-500 \mathrm{~m})$. The

140 spatial coverage of the occurrences was limited to the administrative boundaries of the regions of

141 Lazio, Abruzzo and Molise, comprising 32,523 $\mathrm{km}^{2}$, of which over one-third $\left(12,309 \mathrm{~km}^{2}\right)$ had

142 forest cover (fig. 1). The whole database was filtered from all the pseudo-replicated points that

143 fell into the same $1 \mathrm{~km}^{2}$ grid. The database was further cleared of all the occurrences that were

144 located in unrealistic locations (i.e. non-forested areas), except for those $<300 \mathrm{~m}$ away from the

145 nearest forest patch, which were relocated to the nearest patch. Every occurrence was

146 georeferenced with GPS. Hence, for our purposes, the error in location was assumed to be the

147 same across the three datasets. The final database consisted of 170 occurrence points of $C$.

148 brachydactyla (tab. 1), of which 119 were supplied by the MITO2000 database, exceeding the

149 recommended minimum sample size (Wisz et al., 2008).

150 Species distribution models

151 The SDMs were implemented using five environmental predictors, correlated with forest

152 structure, productivity and the degree of fragmentation, at a spatial resolution of $30 \mathrm{~m}$. First, a

153 habitat type map, consisting of 12 classes, was created from the regional forest maps (Marchetti

154 et al. 2009; Garfî and Marchetti 2011; Anonymous 2012), aggregating all of the non-forest

155 habitat and distinguishing 11 forest types (tab. 1). Three landscape metrics were then calculated

156 from the habitat map, using FRAGSTATS v. 4 software (McGarigal, Cushman \& Ene, 2012): 1)

157 Diversity (H'), a measure of patch type diversity within the landscape (Shannon \& Wiener,

158 1949); 2) edge density (ED) which expresses the density ( $\mathrm{m} \mathrm{ha}^{-1}$ ) of boundaries; 3) the

159 aggregation index (AI) which measures the degree of aggregation between forest patches (He, 
160 DeZonia \& Mladenoff, 2000). The first two metrics were implemented using a moving window

161 of $1000 \mathrm{~m}$, as they can show little variability among different spatial scales and we were

162 interested in landscape features, avoiding the influence of small patches (Uuemaa, Roosaare \&

163 Mander, 2005). By contrast, for AI a $300 \mathrm{~m}$ moving window was used, as we were interested, in

164 this case, in controlling how small patches aggregate across the landscape, according also to the

165 home range and territory size of the short-toed treecreeper (Cramp, 1988). Accordingly, we

166 chose to use the normalized difference vegetation index (NDVI) as a proxy of forest cover and

167 structure, integrating it into the modelling framework. The NDVI is highly correlated with the

168 leaf area index and the net primary productivity (Myneni et al., 1995; Pettorelli et al., 2005; Lee

169 et al., 2006) and was calculated from Landsat 8 multispectral images, with $30 \mathrm{~m}$ spatial

170 resolution. NDVI was computed over a mosaic of five images with cloud cover $<10 \%$, collected

171 between July and August 2013, which had undergone the atmospheric correction procedure.

172 Finally, altitude was integrated through a digital elevation model (DEM) provided by the

173 National Institute for Environmental Protection and Research (ISPRA), available at

174 http://www.sinanet.isprambiente.it/it.

175 Spatial autocorrelations of the environmental predictors within occurrence points were tested

176 through a Mantel test in order to detect any spatial autocorrelations among occurrences (fig. S1).

177 Analyses were carried out with the R package 'ecospat' (Broennimann, Di Cola \& Guisan, 178 2016).

179 Among the eight selected algorithms, the maximum entropy (ME) used presence-only points in 180 combination with background samples, using only quadratic and hinge features to avoid 181 overfitting (Phillips, Anderson \& Schapire, 2006; Elith et al., 2011). The other algorithms, which 182 were supplied with pseudo-absences and true absences, were: an artificial neural network (ANN; 
183 Segurado and Araujo 2004), classification tree analyses (CTA; Breiman et al. 1984; De'ath

184 2002), flexible discriminant analyses (FDA; Hastie et al. 1994), generalized boosting model

185 (GBM; Friedman 2001), generalized linear model (GLM; McCullagh and Nelder 1989),

186 multivariate additive regression spline (MARS; Moisen and Frescino 2002) and random forest

187 (RF; Breiman 2001) (tab. 2). Ten thousand absence points were sampled in the environmental

188 background (Elith et al., 2006), comprising 975 points of actual absence derived from the

189 MITO2000 database and 9025 pseudo-absences, randomly selected within the area where the

190 logistic output of ME was less than 0.2 (Chefaoui \& Lobo, 2008; Wisz \& Guisan, 2009),

191 representing an adequate number of pseudo-absences (Barbet-Massin et al., 2012). SDMs were

192 trained using $70 \%$ of randomly selected occurrences, while the remaining $30 \%$ were used for

193 testing; the procedure was iterated 30 times (except for ME with 50 iterations) (further details are

194 provided in table 2). The area under the curve (AUC) of the receiving operating characteristic

195 (Hanley \& McNeil, 1982) was used to evaluate the predictive power of the SDMs. To improve

196 the readability of SDM outputs, sensitivity (i.e. the proportions of correct positive prediction)

197 and specificity (i.e. the proportion of correct negative prediction) and the true skill statistic (TSS)

198 were also reported (Allouche, Tsoar \& Kadmon, 2006; Lobo, Jiménez-Valverde \& Real, 2008).

199 The importance of each environmental predictor was calculated following Thuiller et al. (2009).

200 Analyses were carried out with the software MaxEnt (Phillips, Anderson \& Schapire, 2006) and

201 the biomod2 package integrated in R (Thuiller et al., 2009; R Core Team, 2015; Thuiller,

202 Georges \& Engler, 2015).

203 Abundance estimation

204 Abundance was estimated in two forest stands used as test sites of the LIFE+ ManFor C.BD:

205 Bosco Pennataro Regional Forest and Chiarano-Sparvera Regional Forest. Bosco Pennataro (BP, 
$20641^{\circ} 44^{\prime} \mathrm{N}, 14^{\circ} 11^{\prime} \mathrm{E}, 1000 \mathrm{~m}$ a.s.1.) consists of a multi-layered high forest stand dominated by

207 turkey oak (Quercus cerris). Chiarano-Sparvera (CS, $41^{\circ} 51^{\prime} \mathrm{N}, 13^{\circ} 57^{\prime} \mathrm{E}, 1700 \mathrm{~m}$ a.s.1.) is a

208 pure beech (Fagus sylvatica) forest, in transition from coppice to high forest. Following a

209 systematic design, 27 and 23 sampling points, $125.5 \mathrm{~m} \mathrm{(} \pm 19.7 \mathrm{sd})$ away from one another, were

210 selected in BP and CS, respectively. Surveys were carried out from May to June (2012 in CS;

2112013 in BP) from sunrise till 11:00 a.m. At every point, each individual detected by aural/visual

212 cues during a five-minute count was recorded. Each point was visited two to six times (average =

$213 \quad 3.4 ;$ total $=177)$.

214 Local abundance was estimated with N-mixture models (Royle, 2004b). This approach considers

215 local abundance (i.e. abundance estimated in each sampling point) as an independent random

216 point process (Royle, 2004a). Two separate models were built for BP and CS, respectively: with

217 and without detectability variation among occasions. Model fit and overdispersion (also called c-

218 hat) was tested through a Pearson $\chi^{2}$ goodness-of-fit test, with 1000 bootstrap resampling

219 (MacKenzie \& Bailey, 2004). Model selection proceeded through Akaike's Information

220 Criterion, which assigns scores both to the likelihood of the model and the number of parameters

221 included (Burnham \& Anderson, 2002). Spatial dependence of estimates was assessed with the

222 Moran test and index calculation (Moran, 1950). Analyses were carried out using the packages

223 unmarked (Fiske \& Chandler, 2011), AICmodavg (Mazerolle, 2015) and spdep (Bivand \& Piras,

224 2015) implemented in R (R Core Team, 2015).

\section{Statistical analyses}

226 Local abundances (i.e. the abundance at every sampling point) in BP and CS were tested for

227 differences with an $F$-test, followed by a $t$-test. Habitat suitability values, defined as the SDM

228 outputs, were then extracted from a discrete area surrounding every abundance point. Width of 
229 the area in question was proportional to local abundance and was derived by transforming the

230 estimated population size (i.e. the sum of local abundances) into densities (ind./ha): the area of

231 interest for density transformation was given by the minimum convex polygon among the

232 sampling points. The difference between BP and CS environmental suitability values was tested

233 by an $F$-test and a $t$-test. The landscape metric values were also tested for difference with the

234 same methods.

235 The relationship between abundance and environmental suitability can form a triangular

236 envelope, where increasing values of environmental suitability are matched by increasing values

237 of the maximum abundance, not just the mean abundance (VanDerWal et al., 2009). Therefore,

238 quantile regression can best provide the opportunity to explore the relation between

239 environmental suitability and the upper quantiles of the abundance (Cade, Noon \& Flather,

240 2005). The triangular envelope can predict maximum abundance, given a suitability value, due to

241 the increase in the slope of regressions of upper quantiles, while intercepts remain similar

242 (VanDerWal et al., 2009). However, two factors can mask the results: first, random variation at

243 every point also due to local limiting factors that are not feasible to model; secondly, the spatial

244 structure of the data, that can generate autocorrelation. Therefore, quantile mixed regressions

245 were implemented to model the abundance as a function of HS values of every SDM, with a null

246 random term and a grouping factor identifying the two locations. The random effect is estimated

247 through best linear prediction (Geraci \& Bottai, 2013). Model fit was assessed for every quantile

248 through comparison of AIC scores with the null model of the corresponding quantile (Burnham

$249 \&$ Anderson, 2002). Statistical analysis was carried out with the lqmm package (Geraci, 2014) in

250 R (R Core Team, 2015).

\section{RESULTS}


252 Each SDM showed an AUC > 0.9, except for FDA (tab. 2). Among them, RF ranked the highest

253 value $(\mathrm{AUC}=1)$. However, the geographical projections of the SDMs proved dissimilar (see

254 supplementary materials, fig. S2). The importance of each environmental predictor had the same

255 pattern for every algorithm, with forest type and NDVI proving the most important (fig. 2). The

256 importance of the three landscape metrics (H, AI, ED) indicates that the spatial configuration of

257 landscape structures exerts a major influence on potential distribution.

258 Abundance models that performed best in both study areas were those in which detectability was

259 invariant between sessions. Detectability was $0.34( \pm 0.11 \mathrm{SE})$ in Bosco Pennataro and $0.21( \pm$

$2600.27 \mathrm{SE})$ in Chiarano Sparvera. Local abundances significantly differed between the two areas $(F$

$261=0.77, \mathrm{p}=0.53 ; t=-3.57, \mathrm{p}<0.001)$, and mean estimates were $1.54( \pm 0.52 \mathrm{SE})$ in $\mathrm{BP}$ and 0.86

262 ( \pm 1 SE) individuals/point in CS. Both models returned a good fit, with no overdispersion (BP: $\chi^{2}$

$263=64.3, \mathrm{p}=0.997, \mathrm{c}-\mathrm{hat}=0.687 ; \mathrm{CS}: \chi^{2}=52.5, \mathrm{p}=0.391$, c-hat $\left.=1\right)$. Estimates did not show

264 spatial autocorrelation in the two forest stands, obtaining a Moran I of $0.11(\mathrm{p}=0.14)$ and -0.26

$265(\mathrm{p}=0.92)$ for BP and CS, respectively.

266 Habitat suitability also proved different between BP and CS, for every SDM (tab. 3), and HS was

267 higher in BP. In parallel, the values of landscape metrics significantly differed between the two

268 forest stands except for edge density (tab. 3). Specifically, Bosco Pennataro landscape structure

269 resulted in larger and less scattered patches $(\mathrm{AI}=98)$, equally distributed among types $\left(\mathrm{H}^{\prime}=\right.$

270 0.93), compared to $\mathrm{CS}\left(\mathrm{AI}=92.6 ; \mathrm{H}^{\prime}=0.76\right)$. Hence, landscape metrics showed a more

271 fragmented landscape in CS than in BP, as expected.

272 Quantile regression showed a positive relationship between abundance and HS (fig. 3 and fig.

273 S3). No differences emerged for the regression slope of each quantile, while intercept values

274 proved more variable. Moreover, the majority of slopes were not significant except for CTA, 
275 GBM and GLM (see supplementary materials, tab. S1), even if AIC comparison indicated that

276 most of the quantiles performed better than the corresponding null model (tab. 4).

\section{DISCUSSION}

278 We examined the abundance and habitat suitability resulting from many algorithms for species 279 distribution modelling (Elith et al., 2006; Li \& Wang, 2013) of a forest-dwelling passerine in a 280 region with different degrees of fragmentation. Although SDMs showed high AUCs, geographical projections varied quite substantially among algorithms, even if their explanatory variables followed the same pattern of importance scoring. Moreover, AUC computation for ME differs from the other algorithms, which made use of (pseudo) absences, being not comparable (Yackulic et al., 2013). Several studies that compared SDM outputs differed substantially (Segurado \& Araujo, 2004; Elith et al., 2006; Moisen et al., 2006; Meynard \& Quinn, 2007). Among those that based their comparison on AUC, ANN was favoured over CTA and GLM (Segurado \& Araujo, 2004) and GBM and ME were favoured over MARS and GLM (Elith et al., 2006). GBM and GLM were preferred to CTA also by other authors (Moisen et al., 2006; Meynard \& Quinn, 2007). What emerged from the literature is that complex models usually outperform simple models, especially when they involve specialist species (Jiménez-Valverde, Lobo \& Hortal, 2008; Li \& Wang, 2013). Indeed, our results are not totally concordant with findings elsewhere, simple models like GLM and GBM having scored higher AUC values. However, the use of AUC has been criticised by many authors even if there are currently no consensus methods to assess the predictability of SDMs (Austin, 2007; Lobo, Jiménez-Valverde \& Real, 2008). Specifically, the AUC does not consider the goodness of fit of a model and it is higher when more pseudo-absences in unsuitable localities are included in the model (Lobo,

297 Jiménez-Valverde \& Real, 2008). Nevertheless, its use is still widespread (Elith \& Graham, 
298 2009; Barbet-Massin et al., 2012). It should also be pointed out that, even if we used a large

299 number of (pseudo) absences, we also employed a larger number of presence points than what is

300 usually found in the literature (e.g. Pearson et al., 2007).

301 SDM output can usually be considered as a probability of occurrence, somewhat related to

302 habitat suitability (Franklin, 2009). In the case of ME, this is achieved after logistic

303 transformation (Phillips \& Dudík, 2008). This approach has been criticised because of the

304 frequent violation of two major assumptions: randomness of the samples and constant

305 detectability among individuals (Royle et al., 2012; Merow, Smith \& Silander, 2013). Indeed, the

306 logistic output uses a rather subjective intercept of 0.5 , which is valid, though its reliability is not

307 proven (Royle et al., 2012). Use of pseudo-absence also needs caution, since the background in

308 which sampling takes place has both suitable and unsuitable locations (Pearce \& Boyce, 2006).

309 However, we employed an analytical framework designed to reduce this source of bias. The

310 randomness of the presence points is due to the use of occurrences coming from a standardised

311 monitoring programme. For the same reasons, we assume that the variability in detectability is

312 reduced to the minimum, demonstrating this issue also in the two forests where we estimated

313 abundance (i.e. BP and CS). Finally, our use of the logistic output of ME, as well as of its

314 subjective intercept of 0.5 , is based upon the consideration that $37 \%$ of the study area is covered

315 in forest. Therefore, assuming an intercept of 0.5 does not seem too far from reality scenario.

316 Indeed, ME has been proved to be one of the most reliable SDMs when only presence data are

317 available (Franklin, 2009; Merow, Smith \& Silander, 2013). Our use of ME, moreover, was

318 functional to the selection of pseudo-absences, which were not selected within the entire region,

319 but only in a restricted area considered unsuitable by ME. As a consequence, we also assume that

320 our method of selecting pseudo-absence greatly reduced an eventual bias. At the very end, we 
321 considered SDM outputs as a habitat suitability index, which we could assume to be related to

322 actual environmental suitability (VanDerWal et al., 2009; Brambilla \& Ficetola, 2012).

323 For reliable modelling, it is necessary to use ecologically relevant environmental predictors

324 (Austin, 2007), even if it is not possible to include every environmental variable thought to affect

325 the distribution of a species (Elith \& Leathwick, 2009). We based the choice of environmental

326 variables on both the known species-habitat relationships and on the possibility of obtaining

327 relevant information to steer management, relying on forest type, structure, productivity and

328 fragmentation. Forest type and NDVI proved the most important variables in predicting the

329 distribution of the short-toed treecreeper. The NDVI is not only positively correlated to net

330 primary productivity (Myneni et al., 1995; Pettorelli et al., 2005), but also to the structural

331 complexity of forests (Manes et al., 2010). As a consequence, among the same forest type, a

332 higher NDVI is related, given that all other variables are comparable, to more structured, multi-

333 layered forests or to forest patches that are more productive or that have a higher leaf area index,

334 where specialist birds can find a more suitable habitat (Newton, 1994; Carrillo-Rubio et al.,

335 2014). Obviously, this conclusion also depends on the patch size and the degree of

336 fragmentation, which are intertwined with NDVI and forest type. Indeed, a substantial influence

337 of landscape structure in defining habitat suitability was clearly apparent when taking into

338 account the three metrics together. Responses to fragmentation are species-specific and, usually,

339 the more specialist a species, the more negative its response (Devictor, Julliard \& Jiguet, 2008;

340 Rueda et al., 2013). SDM outputs showed higher HS in localities in less fragmented landscapes,

341 in agreement with the literature on forest specialist birds (Fahrig, 2003).

342 We used hierarchical statistical analysis of abundance to obtain unbiased estimates, corrected for

343 detectability (Royle, 2004a). The significant difference in abundances between Bosco Pennataro 
344 and Chiarano-Sparvera is matched by the difference in the suitability of the two forests.

345 Therefore, differences in abundance, HS and landscape metrics matched the same pattern: in

346 locations with more degraded forest, both HS and abundance scored lower values, even though

347 abundance showed higher variability, confounding the hypothesised relationships with HS.

348 Our results suggest that there is a positive relationship between habitat suitability and treecreeper

349 abundance, even if the hypothesised triangular envelope (VanDerWal et al., 2009) did not

350 emerge. However, its predictive power was quite weak, due to high abundance variability in both

351 low and high HS locations. Extensive research has yielded little evidence for the relationship

352 between demographic parameters and HS (Pearce \& Ferrier, 2001; Nielsen et al., 2005; Jiménez-

353 Valverde et al., 2009). Related findings are often discordant (Jiménez-Valverde et al., 2009;

354 Tôrres et al., 2012) and many concerns are raised on the controversial and often unconfirmed

355 empirical relationships between ecological processes and landscape patterns (Turner, Gardner \&

356 O’Neill, 2001; Kupfer, 2012). That said, the relationship can be masked by the many unmodelled

357 environmental variables that can conceal local suitability (Lobo, Jiménez-Valverde \& Real,

358 2008). For this reason, VanDerWal et al. (2009) concluded that just the upper limit of

359 abundance, and not its mean value, is predictable from HS. However, this relationship has been

360 widely found to be very weak due to the difficulty to obtain reliable estimates of both abundance

361 and HS (Jiménez-Valverde, 2011; Oliver et al., 2012; Tôrres et al., 2012). Some exceptions are

362 presumably due to the use of indexes of abundance, instead of actual estimates (de Moraes

363 Weber \& Viveiros Grelle, 2012; Gutiérrez et al., 2013). Indeed, our approach was based not only

364 on abundance estimates but also on HS values from different algorithms and averaged over the

365 likely home range size. Moreover, our use of landscape features as predictive variables could 
366 have enhanced model performance since other studies (e.g. Tôrres et al., 2012), based mostly on

367 climatic variables, found positive but weaker relationships between HS and abundance.

368 This result, though confirming the existence of a relationship, also highlights the limits of the

369 SDM approach, suggesting that low HS can also occur in areas of high abundance, probably due

370 to environmental factors that are not considered in modelling which may increase the actual HS

371 of the area.

372 CONCLUSION

373 Birds are considered good biodiversity indicators, especially to monitor habitat alteration (e.g.

374 fragmentation) (Gregory et al., 2008; Carrillo-Rubio et al., 2014; Czeszczewik et al., 2014). For

375 instance, in the context of biotic homogenization, one likely effect is the disappearance of

376 specialist species which are more closely associated to unaltered forests (McKinney \&

377 Lockwood, 1999). Negative effects of habitat alteration can persist over years (Kendrick et al.,

378 2014). Thus identification of the main species-habitat relationships is important to prevent the

379 disappearance of more susceptible species (Villard, Trzcinski \& Merriam, 1999; King \&

380 DeGraaf, 2000). Further, fragmentation can cause the disappearance of the specialist component

381 of biodiversity (Fahrig, 2003). Such processes can alter biological, ecological and demographic

382 traits like brood survival and growth (Suorsa et al., 2003; Le Tortorec et al., 2012), occupancy or

383 population size (Schmiegelow, Machtans \& Hannon, 1997; Villard, Trzcinski \& Merriam, 1999;

384 Cooper \& Walters, 2002). Through SDMs, such results can be transposed into geographic

385 projection and inform conservationists and practitioners (Ferrier et al., 2007; Maiorano et al.,

386 2015). Therefore, modelling how fragmentation can affect the distribution of a species and

387 understand the eventual relations with population decrease, can greatly improve conservation and

388 management plans. 
389 A forest landscape is, in most European cases, a human-modified landscape whose properties,

390 like patch size, can affect many species (Gil-Tena, Torras \& Saura, 2008). Our approach takes

391 into account such issues in order to provide information-based advice. In this way, we define the

392 relationships between a species and some "directly adjustable" landscape features. The Chiarano-

393 Sparvera forest stand is naturally located in a more fragmented landscape than is Bosco

394 Pennataro. Hence, the abundance response (i.e. decrease) of the short-toed treecreeper is matched

395 by habitat choice. Fragmentation, extensive rejuvenation of forest stands and tree plantations are

396 all factors that can contribute to alter the suitability of an area. Since habitat alteration can

397 decrease species abundance sooner than effectively reducing their geographic range (Shoo,

398 Williams \& Hero, 2005), identification of areas of low HS, where impact on abundance is more

399 likely to cause local extinctions, could act as an early warning for species conservation. In our

400 approach, these threats can occur on a large scale, can be related to possible changes in

401 abundance and then used to inform practitioners and managers. Moreover, prediction of future

402 land use scenarios can be implemented.

403 However, our results are a case study, limited to a single specialist species, strictly linked to

404 mature well-preserved forests. This approach could be extended over different kinds of habitats

405 and species, other than forests. Moreover, the modelling should be refined to include other

406 potential resources and limiting factors, whether biotic or abiotic, in order to obtain more robust

407 HS prediction (Guisan \& Thuiller, 2005). The magnitude of the relationship between HS and

408 abundance can then be used as a form of model validation (Lobo, Jiménez-Valverde \& Real,

409 2008), thus helping to steer sound land use management and conservation planning.

\section{ACKNOWLEDGEMENT}


411 We are grateful to Jorge Soberón for valuable advice on the manuscript. We are also grateful to

412 an anonymous reviewer for good advices. We are grateful to the secretary of the project

413 MITO2000, especially to Simonetta Cutini, who patiently organized part of the dataset. Thanks

414 are also due to Andrea Mancinelli for having assisted in many ornithological surveys and, in

415 general, to the staff of the Isernia and Castel di Sangro Ufficio Territoriale Biodiversità del

416 Corpo Forestale dello Stato (National Forest Service) for their logistic support. We are most

417 grateful to the association ARDEA (www.ardeaonlus.it) for supporting our field work with its

418 large number of volunteers.

\section{LITERATURE}

420 Allouche O., Tsoar A., Kadmon R. 2006. Assessing the accuracy of species distribution models:

421 prevalence, kappa and the true skill statistic (TSS). Journal of Applied Ecology 43:1223-

422

423

424

425

426

427

428

429 1232. DOI: 10.1111/j.1365-2664.2006.01214.x.

Austin M. 2007. Species distribution models and ecological theory: a critical assessment and some possible new approaches. Ecological Modelling 200:1-19. DOI: 10.1016/j.ecolmodel.2006.07.005.

Barbet-Massin M., Jiguet F., Albert CH., Thuiller W. 2012. Selecting pseudo-absences for species distribution models: how, where and how many? Methods in Ecology and Evolution 3:327-338. DOI: 10.1111/j.2041-210X.2011.00172.x.

Bearer S., Linderman M., Huang J., An L., He G., Liu J. 2008. Effects of fuelwood collection and timber harvesting on giant panda habitat use. Biological Conservation 141:385-393. DOI: 10.1016/j.biocon.2007.10.009.

Bender DJ., Tischendorf L., Fahrig L. 2003. Using patch isolation metrics to predict animal movement in binary landscapes. Landscape Ecology 18:17-39. 
434 BirdLife International. 2012.Certhia brachydactyla

435 Bivand R., Piras G. 2015. Comparing implementations of estimation methods for spatial 436 econometrics. Journal of Statistical Software 63.

437 Blondel J., Ferry C., Frochot B. 1981. Point counts with unlimited distance. In: Ralph JC, Scott 438 JM eds. Estimating Numbers of Terrestrial Birds. Asilomar, California, USA: Studies in $439 \quad$ Avian Biology, 414-420.

Brambilla M., Ficetola GF. 2012. Species distribution models as a tool to estimate reproductive parameters: a case study with a passerine bird species. Journal of Animal Ecology 81:781-

Breiman L. 2001. Random forests. Machine learning 45:5-32. DOI: 10.1023/A:1010933404324.

Broennimann O., Di Cola V., Guisan A. 2016. ecospat: Spatial Ecology Miscellaneous Methods.

Burnham KP., Anderson DR. 2002. Model selection and multimodal inference. New York:

Calladine J., Bray J., Broome A., Fuller RJ. 2015. Comparison of breeding bird assemblages in Springer-Verlag.

Cade BS., Noon BR., Flather CH. 2005. Quantile regression reveals hidden bias and uncertainty in habitat models. Ecology 86:786-800. 2014. Use of multispecies occupancy models to evaluate the response of bird communities to forest degradation associated with logging. Conservation biology 28:1034-44. DOI: 
457

458

459

460

461

462

463

464

465

466

467

468

469

470

471

472

473

474

475

476

477

478

479

10.1111/cobi. 12261 .

Chefaoui RM., Assis J., Duarte CM., Serrão EA. 2015. Large-scale prediction of seagrass distribution integrating landscape metrics and environmental factors: the case of Cymodocea nodosa (Mediterranean-Atlantic). Estuaries and Coasts. DOI: 10.1007/s12237015-9966-y.

Chefaoui RM., Lobo JM. 2008. Assessing the effects of pseudo-absences on predictive distribution model performance. Ecological Modelling 210:478-486. DOI: 10.1016/j.ecolmodel.2007.08.010.

Cody ML. 1985. Habitat selection in birds. Academic Press.

Cooper CB., Walters JR. 2002. Independent e $\square$ ects of woodland loss and fragmentation on Brown Treecreeper distribution. Biological Conservation.

Craig MD. 2007. The short-term effects of edges created by forestry operations on the bird community of the jarrah forest, south-western Australia. Austral Ecology 32:386-396. DOI: 10.1111/j.1442-9993.2007.01710.x.

Cramp S. (ed.) 1988. The Birds of the Western Paleartic. Oxford, UK: Oxford University Press.

Czeszczewik D., Zub K., Stanski T., Sahel M., Kapusta A., Walankiewicz W. 2014. Effects of forest management on bird assemblages in the Bialowieza Forest, Poland. iForest Biogeosciences and Forestry. DOI: 10.3832/ifor1212-007.

Darvishi A., Fakheran S., Soffianian A. 2015. Monitoring landscape changes in Caucasian black grouse (Tetrao mlokosiewiczi) habitat in Iran during the last two decades. Environmental monitoring and assessment 187:4659. DOI: 10.1007/s10661-015-4659-3.

De'ath G. 2002. Multivariate regression trees: a new technique for modeling speciesenvironment relationships. Ecology 83:1105-1117. DOI: 10.1890/0012- 
480

481

482

483

484

485

486

487

488

489

490

491

492

493

494

495

496

497

498

499

500

501

502

$$
\text { 9658(2002)083[1105:MRTANT]2.0.CO;2. }
$$

Devictor V., Julliard R., Jiguet F. 2008. Distribution of specialist and generalist species along spatial gradients of habitat disturbance and fragmentation. Oikos 117:507-514. DOI: 10.1111/j.0030-1299.2008.16215.x.

Donald PF., Fuller RJ., Evans AD., Gough SJ. 1998. Effects of forest management and grazing on breeding bird communities in plantations of broadleaved and coniferous trees in western England. Biological Conservation 85:183-197. DOI: 10.1016/S0006-3207(97)00114-6.

Elith J., Graham CH., Anderson RP., Dudik M., Ferrier S., Guisan A., Hijmans RJ., Huettmann F., Leathwick JR., Lehmann A., Li J., Lohmann LG., Loiselle BA., Manion G., Moritz C., Nakamura M., Nakazawa Y., Overton JMC., Peterson AT., Phillips SJ., Richardson K., Scachetti-Pereira R., Schapire RE., Soberon J., Williams S., Wisz MS., Zimmermann NE. 2006. Novel methods improve prediction of species' distributions from occurrence data. Ecography 29:129-151.

Elith J., Phillips SJ., Hastie T., Dudík M., Chee YE., Yates CJ. 2011. A statistical explanation of MaxEnt for ecologists. Diversity and Distributions 17:43-57. DOI: 10.1111/j.14724642.2010.00725.x.

Elith J., Graham CH. 2009. Do they? How do they? WHY do they differ? On finding reasons for differing performances of species distribution models. Ecography 32:66-77. DOI: 10.1111/j.1600-0587.2008.05505.x.

Elith J., Leathwick JR. 2009. Species distribution models: ecological explanation and prediction across space and time. Annual Review of Ecology, Evolution, and Systematics 40:677-697. DOI: 10.1146/annurev.ecolsys.110308.120159.

Escobar MAH., Uribe S V., Chiappe R., Estades CF. 2015. Effect of clearcutting operations on 
503

504

505

506

507

508

509

510

511

512

513

514

515

516

517

518

519

520

521

522

523

524

525

the survival rate of a small mammal. Plos One 10:e118883. DOI:

10.1371/journal.pone.0118883.

Fahrig L. 2003. Effects of habitat fragmentation on biodiversity. Annual Review of Ecology, Evolution, and Systematics 34:487-515. DOI: 10.1146/annurev.ecolsys.34.011802.132419.

Farashi A., Kaboli M., Karami M. 2013. Predicting range expansion of invasive raccoons in northern Iran using ENFA model at two different scales. Ecological Informatics 15:96-102. DOI: 10.1016/j.ecoinf.2013.01.001.

Ferrier S., Manion G., Elith J., Richardson K. 2007. Using generalized dissimilarity modelling to analyse and predict patterns of beta diversity in regional biodiversity assessment. Diversity and Distributions 13:252-264. DOI: 10.1111/j.1472-4642.2007.00341.x.

Fiske IJ., Chandler RB. 2011. unmarked : an R package for fitting hierarchical models of wildlife occurrence and abundance. Journal of Statistical Software 43:1-23.

Fornasari L., Londi G., Buvoli L., Tellini Florenzano G., La Gioia G., Pedrini P., Brichetti P., de Carli E. 2010. Distribuzione geografica e ambientale degli uccelli comuni nidificanti in Italia, 2000-2004 (dati del progetto MITO2000). Avocetta 34:5-224.

Franklin J. 2009. Mapping species distributions: spatial inference and prediction. Cambridge: Cambridge University Press. DOI: 10.1017/CBO9781107415324.004.

Friedman JH. 2001. Greedy function approximation: a gradient boosting machine. The Annals of Statistics 29:1189-1232.

Geraci M. 2014. Linear Quantile Mixed Models : The lqmm Package for Laplace Quantile Regression. Journal of Statistical Software 57:1-29.

Geraci M., Bottai M. 2013. Linear quantile mixed models. Statistics and Computing 24:461-479. DOI: $10.1007 / \mathrm{s} 11222-013-9381-9$. 
526 Gil-Tena A., Torras O., Saura S. 2008. Relationship between forest landscape structure and avian 527 species richness in NE Spain. Ardeola 55:27-40.

528 Gregory RD., Vořišek P., Noble DG., Van Strien A., Klvaňová A., Eaton M., Gmelig Meyling

529 AW., Joys A., Foppen RPB., Burfield IJ. 2008. The generation and use of bird population 530 indicators in Europe. Bird Conservation International 18:223-244. DOI:

$531 \quad 10.1017 / \mathrm{S} 0959270908000312$.

532 Grinnell J. 1917. The niche-relationships of the California thrasher. The Auk 34:427-433.

533 Guisan A., Thuiller W. 2005. Predicting species distribution: offering more than simple habitat 534 models. Ecology Letters 8:993-1009. DOI: 10.1111/j.1461-0248.2005.00792.x.

535 Gutiérrez D., Harcourt J., Díez SB., Gutiérrez Illán J., Wilson RJ. 2013. Models of presence-

536 absence estimate abundance as well as (or even better than) models of abundance: the case 537 of the butterfly Parnassius apollo. Landscape Ecology 28:401-413. DOI: 10.1007/s10980$538 \quad 013-9847-3$.

539 Hanley J., McNeil B. 1982. The meaning and use of the area under a receiver operating $540 \quad$ characteristic (ROC) curve. Radiology 143:29-36.

541 Hastie T., Tibshirani R., Buja A. 1994. Flexible discriminant analysis by optimal scoring.

$542 \quad$ Journal of the American Statistical Association 89:1255-1270.

543 He HS., DeZonia BE., Mladenoff DJ. 2000. An aggregation index (AI) to quantify spatial $544 \quad$ patterns of landscapes. Landscape Ecology 15:591-601.

545 Holt RD. 2009. Bringing the Hutchinsonian niche into the 21st century: ecological and 546 evolutionary perspectives. Proceedings of the National Academy of Sciences 106:19659547 19665. DOI: 10.1073/pnas.0905137106.

548 Hutchinson GE. 1957. Concluding remarks. Cold Spring Harbor Symposia on Quantitative 
550

551

552

553

554

555

556

557

558

559

560

561

562

563

564

565

566

567

568

569

570

571

Jackson ST., Overpeck JT. 2000. Responses of plant populations and communities to environmental changes of the late quaternary. Paleobiology 26:194-220.

Jiménez-Valverde A., Diniz F., Azevedo EB De., Borges P a. V. 2009. Species distribution models do not account for abundance: the case of arthropods on Terceira Island. Annales Zoologici Fennici 46:451-464. DOI: 10.5735/086.046.0606.

Jiménez-Valverde A. 2011. Relationship between local population density and environmental suitability estimated from occurrence data. Frontiers of Biogeography 3.2:59-61.

Jiménez-Valverde A., Lobo JM., Hortal J. 2008. Not as good as they seem: the importance of concepts in species distribution modelling. Diversity and Distributions 14:885-890. DOI: 10.1111/j.1472-4642.2008.00496.x.

Kendrick SW., Porneluzi PA., Thompson III FR., Morris DL., Haslerig JM., Faaborg J. 2014. Stand-level bird response to experimental forest management in the Missouri Ozarks. The Journal of Wildlife Management 79:50-59. DOI: 10.1002/jwmg.804.

King DI., DeGraaf RM. 2000. Bird species diversity and nesting success in mature, clearcut and shelterwood forest in northern New Hampshire, USA. Forest Ecology and Management 129:227-235. DOI: 10.1016/S0378-1127(99)00167-X.

Kumar S., Stohlgren TJ., Chong GW. 2006. Spatial heterogeneity influences native and nonnative plant species richness. Ecology 87:3186-3199. DOI: 10.1890/00129658(2006)87[3186:SHINAN]2.0.CO;2.

Kupfer JA. 2012. Landscape ecology and biogeography: rethinking landscape metrics in a postFRAGSTATS landscape. Progress in Physical Geography 36:400-420. DOI: 
572 Lee KS., Park YI., Kim SH., Park JH., Woo CS., Jang KC. 2006. Remote sensing estimation of

573 forest LAI in close canopy situation. Korean Journal of Remote Sensing 22:305-311.

574 Li X., Wang Y. 2013. Applying various algorithms for species distribution modelling.

575 Integrative Zoology 8:124-135. DOI: 10.1111/1749-4877.12000.

576 Lobo JM., Jiménez-Valverde A., Real R. 2008. AUC: A misleading measure of the performance 577 of predictive distribution models. Global Ecology and Biogeography 17:145-151. DOI:

$578 \quad 10.1111 / \mathrm{j} .1466-8238.2007 .00358 . x$.

579 Loehle C., Wigley TB., Rutzrnoser S., Gerwin JA., Keyser PD., Lancia RA., Reynolds CJ., Thill 580 RE., Weih R., White DJ., Bohall Wood P. 2005. Managed forest landscape structure and 581 avian species richness in the southeastern US. Forest Ecology and Management 214:279$582 \quad 293$.

583 MacArthur R., Recher H., Cody M. 1966. On the relation between habitat selection and species 584 diversity. The American Naturalist 100:319-332. DOI: 10.2307/2458999.

585 MacKenzie DI., Bailey LL. 2004. Assessing the fit of site-occupancy models. Journal of 586 Agricultural, Biological, and Environmental Statistics 9:300-318. DOI: 10.1198/108571104X3361.

588

589

590

591

592

593

594

Maiorano L., Boitani L., Monaco a., Tosoni E., Ciucci P. 2015. Modeling the distribution of Apennine brown bears during hyperphagia to reduce the impact of wild boar hunting. European Journal of Wildlife Research. DOI: 10.1007/s10344-014-0894-0.

Manes F., Ricotta C., Salvatori E., Bajocco S., Blasi C. 2010. A multiscale analysis of canopy structure in Fagus sylvatica L. and Quercus cerris L. old-growth forests in the Cilento and Vallo di Diano National Park. Plant Biosystems 144:202-210. DOI: $10.1080 / 11263500903560801$. 
595 Martínez-Meyer E., Díaz-Porras D., Peterson a. T., Yáñez-Arenas C. 2013. Ecological niche 596 structure and rangewide abundance patterns of species. Biology letters 9:20120637. DOI: $597 \quad 10.1098 / \mathrm{rsbl} .2012 .0637$.

598 Marvier M., Kareiva P., Neubert MG. 2004. Habitat destruction, fragmentation, and disturbance 599 promote invasion by habitat generalists in a multispecies metapopulation. Risk Analysis $600 \quad 24: 869-879$.

601 Mazerolle MJ. 2015. Package “AICcmodavg.”

602 McCullagh P., Nelder JA. 1989. Generalized linear models. Chapman and Hall.

603 McGarigal K., Cushman SA., Ene E. 2012. FRAGSTATS. DOI: 10.1093/ntr/nts298.

604 McKinney ML., Lockwood JL. 1999. Biotic homogenization: a few winners replacing many 605 losers in the next mass extinction. Trends in Ecology and Evolution 14:450-453. DOI: $606 \quad 10.1016 / \mathrm{S} 0169-5347(99) 01679-1$.

607 Merow C., Smith MJ., Silander JA. 2013. A practical guide to MaxEnt for modeling species' 608 distributions: what it does, and why inputs and settings matter. Ecography 36:1058-1069. 609 DOI: $10.1111 /$ j.1600-0587.2013.07872.x.

610 Meynard CN., Quinn JF. 2007. Predicting species distributions: a critical comparison of the most 611 common statistical models using artificial species. Journal of Biogeography 34:1455-1469. 612 DOI: $10.1111 /$ j.1365-2699.2007.01720.x.

613 Moisen GG., Freeman EA., Blackard JA., Frescino TS., Zimmermann NE., Edwards TC. 2006.

614 Predicting tree species presence and basal area in Utah: a comparison of stochastic gradient 615 boosting, generalized additive models, and tree-based methods. Ecological Modelling 616 199:176-187. DOI: 10.1016/j.ecolmodel.2006.05.021.

617 Moisen GG., Frescino TS. 2002. Comparing Five Modelling Techniques for Prediction Forest 
619 de Moraes Weber M., Viveiros Grelle CE. 2012. Does environmental suitability explain the 620 relative abundance of the tailed tailless bat, Anoura caudifer? Natureza \& Conservaçao 621 10:221-227. DOI: 10.4322/natcon.2012.035.

622 Moran PAP. 1950. Notes on continuous stochastic phenomena. Biometrika 37:17-23. DOI: $623 \quad 10.2307 / 2332142$.

624 Morand S., Bordes F., Blasdell K., Pilosof S., Cornu J-F., Chaisiri K., Chaval Y., Cosson J-F., 625 Claude J., Feyfant T., Herbreteau V., Dupuy S., Tran A. 2015. Assessing the distribution of 626 disease-bearing rodents in human-modified tropical landscapes. Journal of Applied Ecology 52:784-794. DOI: 10.1111/1365-2664.12414.

628

629

630

631

632

633

634

635

636

637

638

639

640

Myneni RB., Hall FG., Sellers PJ., Marshak AL. 1995. The interpretation of spectral vegetation indexes. Transactions on Geoscience and Remote Sensng 33:481-486.

Newton I. 1994. The role of nest sites in limiting the numbers of hole-nesting birds: a review. Biological Conservation 70:265-276. DOI: 10.1016/0006-3207(94)90172-4.

Nielsen SE., Johnson CJ., Heard DC., Boyce MS. 2005. Can models of presence-absence be used to scale abundance? Two studies considering extremes in life history. Ecography 28:197208.

Nixon K., Silbernagel J., Price J., Miller N., Swaty R. 2014. Habitat availability for multiple avian species under modeled alternative conservation scenarios in the Two Hearted River watershed in Michigan, USA. Journal for Nature Conservation 22:302-317. DOI: 10.1016/j.jnc.2014.02.005.

Oliver TH., Gillings S., Girardello M., Rapacciuolo G., Brereton TM., Siriwardena GM., Roy DB., Pywell R., Fuller RJ. 2012. Population density but not stability can be predicted from 
641

642

643

644

645

646

647

648

649

650

651

652

653

654

655

656

657

658

659

660

661

662

663

species distribution models. Journal of Applied Ecology 49:581-590. DOI: 10.1111/j.13652664.2012.02138.x.

Pearce JL., Boyce MS. 2006. Modelling distribution and abundance with presence-only data. Journal of Applied Ecology 43:405-412. DOI: 10.1111/j.1365-2664.2005.01112.x.

Pearce J., Ferrier S. 2001. The practical value of modelling relative abundance of species for regional conservation planning: a case study. Biological Conservation 98:33-43. DOI: 10.1016/S0006-3207(00)00139-7.

Pearson RG., Raxworthy CJ., Nakamura M., Townsend Peterson A. 2007. Predicting species distributions from small numbers of occurrence records: a test case using cryptic geckos in Madagascar. Journal of Biogeography 34:102-117. DOI: 10.1111/j.13652699.2006.01594.x.

Penman., Mahony., Lemckert. 2005. Soil disturbance in integrated logging operations and the potential impacts on a fossorial Australian frog. Applied Herpetology 2:415-424. DOI: $10.1163 / 157075405774483111$.

Pettorelli N., Vik JO., Mysterud A., Gaillard J-M., Tucker CJ., Stenseth NC. 2005. Using the satellite-derived NDVI to assess ecological responses to environmental change. Trends in ecology \& evolution 20:503-10. DOI: 10.1016/j.tree.2005.05.011.

Phillips SJ., Anderson RP., Schapire RE. 2006. Maximum entropy modeling of species geographic distributions. Ecological Modelling 190:231-259. DOI: 10.1016/j.ecolmodel.2005.03.026.

Phillips SJ., Dudík M. 2008. Modeling of species distribution with Maxent: new extensions and a comprehensive evalutation. Ecograpy 31:161-175. DOI: 10.1111/j.2007.09067590.05203.x. 
664 R Core Team. 2015. R: A Language and Environment for Statistical Computing.

665 Royle JA. 2004a. Generalized estimators of avian abundance from count survey data. Animal 666 Biodiversity and Conservation 27:375-386.

667 Royle JA. 2004b. N-mixture models for estimating population size from spatially replicated 668 counts. Biometrics 60:108-15. DOI: 10.1111/j.0006-341X.2004.00142.x.

669 Royle JA., Chandler RB., Yackulic C., Nichols JD. 2012. Likelihood analysis of species 670 occurrence probability from presence-only data for modelling species distributions. Methods in Ecology and Evolution 3:545-554. DOI: 10.1111/j.2041-210X.2011.00182.x.

672 Rueda M., Hawkins BA., Morales-Castilla I., Vidanes RM., Ferrero M., Rodríguez MÁ. 2013.

673 Does fragmentation increase extinction thresholds? A European-wide test with seven forest 674 birds. Global Ecology and Biogeography 22:1282-1292. DOI: 10.1111/geb.12079. 675 Ryberg WA., Hill MT., Painter CW., Fitzgerald LA. 2013. Landscape pattern determines 676 neighborhood size and structure within a lizard population. PLoS ONE 8:e56856. DOI: $677 \quad$ 10.1371/journal.pone.0056856.

678 Schindler S., von Wehrden H., Poirazidis K., Wrbka T., Kati V. 2013. Multiscale performance of 679 landscape metrics as indicators of species richness of plants, insects and vertebrates. 680 Ecological Indicators 31:41-48. DOI: 10.1016/j.ecolind.2012.04.012.

681 Schmiegelow FKA., Machtans CS., Hannon SJ. 1997. Are boreal birds resilient to forest 682 fragmentation? An experimental study of short-term community responses. Ecology $683 \quad 78: 1914-1932$.

684 Segurado P., Araujo MB. 2004. An evaluation of methods for modelling species distributions. 685 Journal of Biogeography 31:1555-1568. DOI: 10.1111/j.1365-2699.2004.01076.x. 686 Shannon CE., Wiener W. 1949. The mathematical theory of communication. Urbana, IL, USA: 
687

688

689

690

691

692

693

694

695

696

697

698

699

700

701

702

703

704

705

706

707

708

709

University of Illinois Press.

Shifley SR., Thompson FR., Dijak WD., Fan Z. 2008. Forecasting landscape-scale, cumulative effects of forest management on vegetation and wildlife habitat: a case study of issues, limitations, and opportunities. Forest Ecology and Management 254:474-483. DOI: 10.1016/j.foreco.2007.08.030.

Shoo LP., Williams SE., Hero JM. 2005. Potential decoupling of trends in distribution area and population size of species with climate change. Global Change Biology 11:1469-1476. DOI: $10.1111 / \mathrm{j} .1365-2486.2005 .00995 . x$.

Suorsa P., Huhta E., Nikula A., Nikinmaa M., Jäntti A., Helle H., Hakkarainen H. 2003. Forest management is associated with physiological stress in an old-growth forest passerine. Proceedings. Biological sciences / The Royal Society 270:963-9. DOI: 10.1098/rspb.2002.2326.

Thuiller W., Lafourcade B., Engler R., Araújo MB. 2009. BIOMOD - A platform for ensemble forecasting of species distributions. Ecography 32:369-373. DOI: 10.1111/j.16000587.2008.05742.x.

Thuiller W., Georges D., Engler R. 2015. Package “biomod2.”

Tôrres NM., De Marco P., Santos T., Silveira L., de Almeida Jácomo AT., Diniz-Filho J a. F. 2012. Can species distribution modelling provide estimates of population densities? A case study with jaguars in the Neotropics. Diversity and Distributions 18:615-627. DOI: 10.1111/j.1472-4642.2012.00892.x.

Le Tortorec E., Helle S., Suorsa P., Sirkiä P., Huhta E., Nivala V., Hakkarainen H. 2012. Feather growth bars as a biomarker of habitat fragmentation in the Eurasian treecreeper. Ecological Indicators 15:72-75. DOI: 10.1016/j.ecolind.2011.09.013. 
710 Tsoar A., Allouche O., Steinitz O., Rotem D., Kadmon R. 2007. A comparative evaluation of

711 presence-only methods for modelling species distribution. Diversity and Distributions

712 13:397-405. DOI: 10.1111/j.1472-4642.2007.00346.x.

713 Turner MG., Gardner RH., O’Neill R V. 2001. Landscape Ecology in Theory and Practice.

714 Pattern and Process. New York, US: Springer-Verlag New York, Inc. DOI:

$715 \quad 10.1007 / b 97434$.

716 Uuemaa E., Mander Ü., Marja R. 2013. Trends in the use of landscape spatial metrics as

717 landscape indicators: a review. Ecological Indicators 28:100-106. DOI:

718 10.1016/j.ecolind.2012.07.018.

719

720

721

722

723

724

725

726

727

728

729

730

731

732

Uuemaa E., Roosaare J., Mander Ü. 2005. Scale dependence of landscape metrics and their indicatory value for nutrient and organic matter losses from catchments. Ecological Indicators 5:350-369. DOI: 10.1016/j.ecolind.2005.03.009.

VanDerWal J., Shoo LP., Johnson CN., Williams SE. 2009. Abundance and the environmental niche: environmental suitability estimated from niche models predicts the upper limit of local abundance. The American naturalist 174:282-91. DOI: 10.1086/600087.

Villard M-A., Trzcinski MK., Merriam G. 1999. Fragmentation effects on forest birds: relative influence of woodland cover and configuration on landscape occupancy. Conservation Biology 13:774-783. DOI: 10.1046/j.1523-1739.1999.98059.x.

Wang Y-H., Yang K-C., Bridgman CL., Lin L-K. 2008. Habitat suitability modelling to correlate gene flow with landscape connectivity. Landscape Ecology:989-1000. DOI: 10.1007/s10980-008-9262-3.

Wiens JA. 1976. Population responses to patchy environments. Annual Review of Ecology and Systematics 7:81-120. DOI: 10.1146/annurev.es.07.110176.000501. 
733 Wisz MS., Hijmans RJ., Li J., Peterson a. T., Graham CH., Guisan a., Elith J., Dudík M.,

734 Ferrier S., Huettmann F., Leathwick JR., Lehmann a., Lohmann L., Loiselle B a., Manion

735 G., Moritz C., Nakamura M., Nakazawa Y., Overton JM., Phillips SJ., Richardson KS.,

736 Scachetti-Pereira R., Schapire RE., Soberón J., Williams SE., Zimmermann NE. 2008.

737 Effects of sample size on the performance of species distribution models. Diversity and

738 Distributions 14:763-773. DOI: 10.1111/j.1472-4642.2008.00482.x.

739 Wisz MS., Guisan A. 2009. Do pseudo-absence selection strategies influence species distribution

740 models and their predictions? An information-theoretic approach based on simulated data.

741 BMC ecology 9:8. DOI: 10.1186/1472-6785-9-8.

742 Yackulic CB., Chandler R., Zipkin EF., Royle JA., Nichols JD., Campbell Grant EH., Veran S.

743 2013. Presence-only modelling using MAXENT: when can we trust the inferences?

744 Methods in Ecology and Evolution 4:236-243. DOI: 10.1111/2041-210x.12004. 


\section{Table $\mathbf{1}$ (on next page)}

Surface of the habitat types included in the analysis within the study area (Abruzzo, Lazione and Molise regions, central Italy) and number of short-toed treecreeper's occurrences. 
Forests and tree plantations habitat types

Area $\left(\mathrm{km}^{2}\right)$

$\mathrm{N}^{\circ}$ of treecreeper's

occurrences
Holm oak (Quercus ilex)

Downy oak (Q. pubescens)

Turkey oak (Q. cerris)

Orno-ostryetum (mixed deciduous woodland

with prevailing Fraxinus ornus and Ostrya

carpinifolia)

Chestnut (Castanea sativa)

Tilio-Acerion

Beech (Fagus sylvatica)

Salix sp. and Populus sp. riparian woodlands and poplar plantations

Tree plantations and bushes

Conifer (both natural and reforestation)

Shrubland and maquis

Non forest
511.9

8

1986.3

13

2412.3

51

1342.4

20

628.1

10

0.12

0

2360.4

40

536.5

12

649.7

8

545

4

1313.1

4

20129.3 


\section{Table 2 (on next page)}

Settings used for species distribution modelling and resulted AUC (area under the curve of the receiving operator characteristic), sensitivity, specificity and TSS (true skills statistic). 


\begin{tabular}{|c|c|c|c|c|c|c|c|}
\hline Full name & Acronym & $\begin{array}{l}\text { Pseudo- } \\
\text { absences }\end{array}$ & Parameters & AUC & Sensitivity & Specificity & TSS \\
\hline $\begin{array}{l}\text { artificial neural } \\
\text { network }\end{array}$ & ANN & 10000 & $\begin{array}{l}\text { 5-fold cross } \\
\text { validation }\end{array}$ & 0.949 & 92.045 & 89.689 & 0.771 \\
\hline $\begin{array}{l}\text { classification } \\
\text { tree analyses }\end{array}$ & CTA & 10000 & $\begin{array}{l}\text { 5-fold cross } \\
\text { validation }\end{array}$ & 0.918 & 85.795 & 93.839 & 0.792 \\
\hline $\begin{array}{l}\text { flexible } \\
\text { discriminant } \\
\text { analyses }\end{array}$ & FDA & 10000 & $\begin{array}{l}\text { Default with } \\
\text { MARS to } \\
\text { increase } \\
\text { predictive power }\end{array}$ & 0.894 & 82.955 & 93.849 & 0.768 \\
\hline $\begin{array}{l}\text { generalized } \\
\text { boosting model }\end{array}$ & GBM & 10000 & $\begin{array}{l}5000 \text { maximum } \\
\text { trees, } 5 \\
\text { interaction and } \\
10 \text {-fold cross } \\
\text { validation }\end{array}$ & 0.961 & 93.75 & 94.529 & 0.842 \\
\hline $\begin{array}{l}\text { generalized } \\
\text { linear model }\end{array}$ & GLM & 10000 & $\begin{array}{l}\text { AIC-based } \\
\text { stepwise model } \\
\text { selection }\end{array}$ & 0.959 & 93.182 & 91.159 & 0.835 \\
\hline $\begin{array}{l}\text { multivariate } \\
\text { additive } \\
\text { regression } \\
\text { splines }\end{array}$ & MARS & 10000 & $\begin{array}{l}\text { Spline knots are } \\
\text { determined } \\
\text { automatically }\end{array}$ & 0.913 & 89.205 & 89.129 & 0.782 \\
\hline $\begin{array}{l}\text { maximum } \\
\text { entropy }\end{array}$ & ME & $\begin{array}{l}\text { No; } 10000 \\
\text { background } \\
\text { points }\end{array}$ & $\begin{array}{l}1000 \text { bootstrap } \\
\text { iterations }\end{array}$ & 0.929 & - & - & - \\
\hline random forest & $\mathrm{RF}$ & 10000 & $\begin{array}{l}750 \text { trees, } 10 \text {-fold } \\
\text { cross validation }\end{array}$ & 1 & 100 & 99.98 & 1 \\
\hline
\end{tabular}




\section{Table 3(on next page)}

Test for differences of landscape metrics and environmental suitability between Bosco Pennataro and Chiarano-Sparvera, based on Species Distribution Models (SDMs).

$\mathrm{H}^{\prime}=$ Shannon index of patch type diversity; $\mathrm{Ed}=$ edge density; $\mathrm{Ai}=$ aggregation index; $F=$ Fisher's test; $t=\mathrm{t}$ test; $\mathrm{P}=\mathrm{p}$ value; model abbreviation are given in table 2 


\begin{tabular}{|c|c|c|c|c|}
\hline & $F$ & $\mathrm{P}$ & $t$ & $\mathrm{p}$ \\
\hline \multicolumn{5}{|l|}{ Metric } \\
\hline $\mathrm{H}^{\prime}$ & 0.065 & 0.000 & 3.3342 & 0.0027 \\
\hline $\mathrm{Ed}$ & 0.3583 & 0.0134 & -1.5038 & 0.1392 \\
\hline $\mathrm{Ai}$ & 0.221 & 0.000 & 7.1504 & 0.000 \\
\hline \multicolumn{5}{|l|}{ Model } \\
\hline ANN & 0.07 & 0.000 & -36 & 0.000 \\
\hline CTA & 4.901 & 0.000 & -9.93 & 0.000 \\
\hline FDA & 2433.4 & 0.000 & -8.06 & 0.000 \\
\hline GBM & 1.137 & 0.748 & -10.91 & 0.000 \\
\hline GLM & 2.996 & 0.008 & -2.949 & 0.002 \\
\hline MARS & 14648 & 0.000 & -4.893 & 0.000 \\
\hline $\mathrm{ME}$ & 46.35 & 0.000 & -4.682 & 0.000 \\
\hline $\mathrm{RF}$ & 30.42 & 0.000 & -4.044 & 0.000 \\
\hline
\end{tabular}

1 


\section{Table 4(on next page)}

DeltaAIC between null model and suitability-dependant model, for the same quantile. 


\begin{tabular}{|c|c|c|c|c|c|c|c|c|}
\hline Quantile & ANN & CTA & FDA & GBM & GLM & MARS & $\mathrm{ME}$ & $\mathrm{RF}$ \\
\hline 0.5 & 0 & 0 & 0 & 0 & 0 & 0 & 0 & 0.50 \\
\hline 0.55 & 0 & 0 & 0 & 0 & 0 & 0 & 0 & 1.20 \\
\hline 0.6 & 0 & 0 & 0 & 0 & 0 & 0 & 0 & 1.39 \\
\hline 0.65 & 0 & 0 & 0 & 0 & 2.88 & 0 & 0 & 1.86 \\
\hline 0.7 & 0 & 0 & 0 & 0 & 0 & 0 & 0.17 & 0.93 \\
\hline 0.75 & 0 & 0 & 0 & 0 & 0 & 0 & 0 & 0 \\
\hline 0.8 & 0 & 0 & 0 & 0 & 4.67 & 23.93 & 0 & 0 \\
\hline 0.85 & 25.74 & 0 & 0 & 0 & 2.17 & 7.79 & 6.29 & 9.14 \\
\hline 0.9 & 0 & 31.93 & 1.15 & 26.85 & 0 & 23.91 & 2.98 & 3.07 \\
\hline 0.95 & 44.78 & 16.49 & 3.38 & 0 & 15.94 & 6.83 & 4.35 & 0 \\
\hline 0.975 & 32.65 & 0 & 0 & 0 & 0 & 31.32 & 0 & 0 \\
\hline 0.99 & 0 & 0 & 0 & 0 & 0 & 0 & 0 & 1.69 \\
\hline
\end{tabular}


Figure 1

Treecreeper's occurrences used to build the distribution models. The study area is located in central-southern Italy, within Abruzzo, Lazio and Molise Regions.

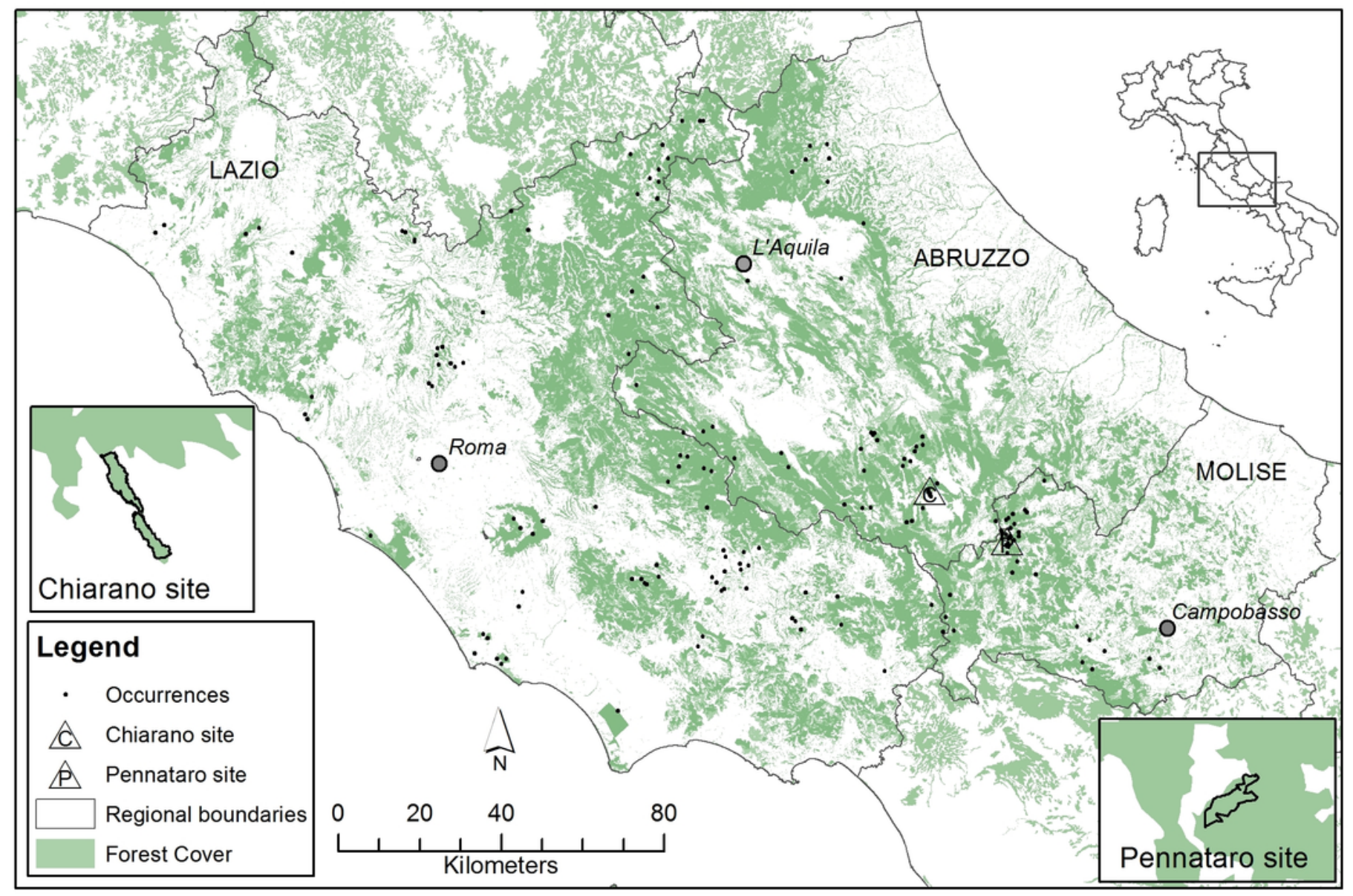




\section{Figure 2 (on next page)}

Variable importance based on different Species Distribution Models (SDMs).

NDVI = Normalized Difference Vegetation Index; $\mathrm{H}^{\prime}=$ Shannon index computed on landscape patch type diversity; $A i$ = aggregation index of landscape patches; Ed = patches' edge density. 


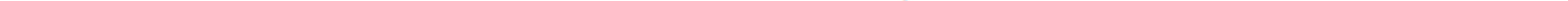




\section{Figure 3 (on next page)}

Scatterplot of abundance versus habitat suitability (as predicted by the Generalised Boosting model, GBM). Regression lines represent the fitted relationship at different quantiles.

Quantiles: solid line $=0.5$ quantile, slope $=0.37, p<0.5$; dashed line $=0.75$, slope $=0.19, p$ $=$ n.s. ; dotted line $=0.95$, slope $=0.13, p=$ n.s. 


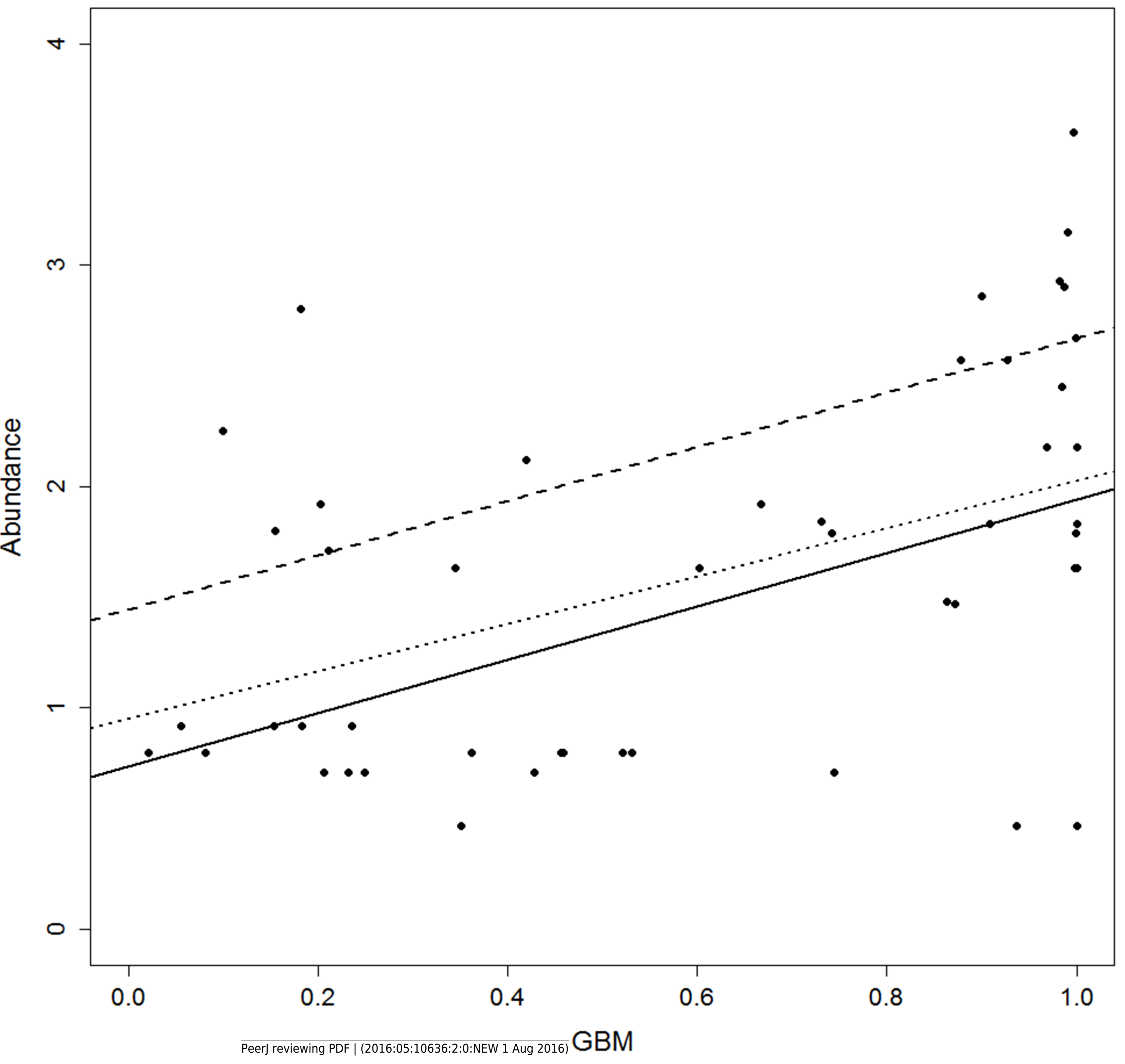

